Tinjauan Pustaka

\title{
TEKNIK PEMERIKSAAN PADA MIKROTROPIA
}

\author{
Lona Diolanda, Sri Handayani Mega Putri
}

\begin{abstract}
Abstrak
Mikrotropia merupakan strabismus sudut kecil (kurang dari $5^{\circ}$ ) yang disertai dengan ARC dan ketajaman stereopsis yang berkurang atau tidak ada sama sekali. Mikrotropia sering disertai dengan sindroma monofiksasi. Ini ditandai dengan adanya fusi perifer dan supresi di daerah sentral (foveal suppresion scotoma) mata yang mengalami deviasi. Mikrotropia dapat dibagi menjadi dua bentuk yaitu mikrotropia primer (mikrotropia with identity dan mikrotropia without identity) dan mikrotropia sekunder. Pemeriksaan diagnostik pada mikrotropia bertujuan untuk menunjukkan adanya penglihatan binokular perifer tanpa disertai penglihatan binokular sentral pada penderita mikrotropia. Pada makalah ini akan membahas karakteristik klinik dan pemeriksaan mikrotropia.
\end{abstract}

Kata kunci: mikrotropia, fusi perifer, skotoma supresi fovea

\begin{abstract}
Microtropia is defined as strabismus with a small deviation (less than $5^{\circ}$ ), combined with Anomalous Retinal Correspondence (ARC) and reduced or absent stereoacuity. Microtropia is often accompanied by monofixation syndrome. It is characterized by peripheral fusion and suppression in the central area (foveal suppresion scotoma) of the misaligned eye. There are two forms of microtropia: primary microtropia (microtropia with identity; microtropia without identity) and secondary microtropia. Diagnostic examination of microtropia aims at demonstrating existence of peripheral binocular vision but no central binocular vision. This paper will discuss about clinical characteristic and diagnostic of microtropia.
\end{abstract}

Keywords: microtropia, peripheral fusion, foveal suppresion scotoma 


\section{PENDAHULUAN}

Strabismus sudut kecil yang dikenal sebagai mikrotropia telah dikenal sejak lebih dari dari 40 tahun yang lalu. Hal ini telah menjadi subjek perdebatan sejak Lang menciptakan istilah untuk menggambarkan strabismus sudut kecil dengan Anomalous Retinal Correspondence (ARC), amplitudo fusi normal dan berkurangnya kemampuan stereopsis. Pada awalnya, Helveston dan Noorden memakai istilah ini untuk kasus-kasus dengan fiksasi eksentrik dan tidak ada pergerakan yang nyata pada coveruncover test. ${ }^{1}$

Mikrotropia merupakan strabismus dengan deviasi kecil dan secara kosmetik tidak mengganggu. Keluhan pada umumnya tidak ada, tapi sebagian kecil pasien mengeluh astenopia karena adanya gangguan penggunaan kedua mata secara bersamaan. Kelainan ini mulanya ditemukan pada pasien strabismus deviasi besar dengan operasi yang sukses, tapi pada evaluasi ditemukan mikrostrabismus dan supresi fovea ${ }^{1,2}$.

Strabismus jenis ini bisa berupa kelainan primer dan bisa juga sekunder dari pengobatan strabismus non operatif, deviasi vertikal dan lesi fovea. Gambaran kliniknya sering membingungkan, sehingga banyak nama yang digunakan untuk ini antara lain, microstrabismus, microtropia, mono-fixational syndrome, retinal slip, fixation disparity, monofixational phoria dan lain-lain ${ }^{1,2,3}$.

Beberapa tes yang bisa digunakan untuk menegakkan diagnosis mikrotropia, diantaranya pemeriksaan prisma cover tes, worth four dot test (WFDT), lensa bagollini dan stereoacuity ${ }^{3,4}$.
Pada makalah ini akan dibahas mengenai teknik-teknik diagnostik pada mikrotropia.

\section{METODE}

Artikel ini ditulis berdasarkan hasil penelusuran dan review kepustakaan mengenai mikrotropia.

\section{HASIL DAN PEMBAHASAN}

Penglihatan binokular dapat diartikan sebagai keadaan visual yang simultan, yang didapat dengan penggunaan yang terkoordinasi dari kedua mata, sehingga bayangan yang sedikit berbeda dan terpisah yang timbul di tiap-tiap mata dianggap sebagai suatu bayangan tunggal dengan proses fusi. Dengan demikian penglihatan binokular dikatakan normal apabila terdapat fusi bifoveal, Normal Retinal Correspondence (NRC) dan tidak terdapat deviasi yang manifes (gambar 1$)^{4,5}$.

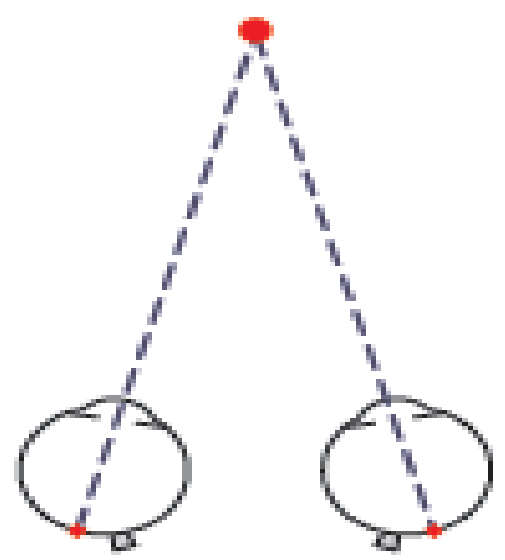

Gambar 1. Penglihatan binokular yang normal ${ }^{5}$

Beda halnya dengan penglihatan binokular yang abnormal yang terjadi ketika bayangan dari obyek yang difiksasi diproyeksikan pada fovea satu mata dan suatu area ekstra fovea pada 
mata yang lain (gambar 2). Penglihatan binokular yang abnormal ini juga bisa terjadi dengan strabismus sudut kecil. Beberapa bentuk dari penglihatan binokular abnormal yaitu, mikrotropia atau sindroma monofiksasi, ARC dengan sudut $>10 \Delta^{6}$.

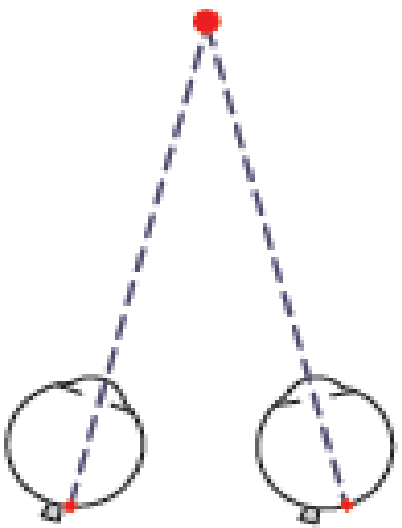

Gambar 2. Anomalous Retinal Correspondence ${ }^{5}$

Penglihatan binokular dibagi dalam tiga tingkat yaitu persepsi simultan, fusi dan stereopsis. Apabila terjadi deviasi visual aksis, maka bayangan pada bidang binokular akan bergeser. Pada keadaan ini akan terjadi dua hal, yaitu:

1. Konfusi yaitu suatu keadaan dimana objek yang berbeda akan diproyeksikan pada area yang koresponden (dua bayangan yang muncul saling tumpang tindih).

2. Diplopia yaitu objek yang identik (titik fiksasi) akan diproyeksikan di retina yang berbeda (di fovea pada satu mata dan di retina perifer mata yang lain) ${ }^{4}$

Sehingga untuk mengatasi masalah penglihatan binokular yang abnormal, ada beberapa mekanisme adaptasi yaitu supresi, $\mathrm{ARC}^{4,7}$.

\section{Definisi Mikrotropia}

Mikrotropia merupakan strabismus dengan deviasi kecil (8-10 prisma dioptri atau kecil dari $5^{\circ}$ ) yang sering diikuti dengan ambliopia anisometropik atau bisa juga berdiri sendiri. Ini merupakan gambaran awal dari gangguan fungsi binokular yang disebabkan oleh penglihatan yang abnormal selama perkembangan penglihatan ${ }^{6,8}$.

Pasien dengan mikrotropia sering disertai dengan sindroma monofiksasi, dimana terjadi fusi di daerah perifer dan supresi di area sentral pada mata yang berdeviasi. Dengan kata lain, kedua fovea tidak bisa bekerja secara simultan. Untuk alasan inilah mikrotropia atau mikrostrabismus bisa disebut juga disebut juga sebagai sindroma monofiksasi ${ }^{8,9}$.

Mikrotropia dapat dibedakan menjadi mikrotropia menjadi primer dan sekunder :1,2,6,10

1. Mikrotropia primer, terjadi kalau tidak ada riwayat strabismus sudut besar sebelumnya dan sering disertai dengan adanya ambliopia. Mikrotropia ini dibagi atas dua tipe yang bisa dibedakan berdasarkan bentuk fiksasi monokular, yaitu:

- Fiksasi eksentrik dengan sudut anomali ARC lebih besar dibanding sudut fiksasi eksentrik. Pada keadaan ini, titik yang digunakan untuk fiksasi oleh mata yang juling koresponden dengan fovea mata yang tidak mengalami deviasi. Keadaan ini dikenal juga dengan istilah microtropia without identity dimana hasil cover test nya terdapat sedikit gerakan.

- Fiksasi eksentrik dengan sudut anomali ARC sama dengan sudut fiksasi eksentrik. Titik fiksasi yang 
digunakan mata yang juling, tidak koresponden dengan mata yang tidak mengalami deviasi. Pada keadaan ini tidak ada gerakan pada pemeriksaan cover test dan dikenal juga dengan istilah microtropia with identity. Pada bentuk ini, area retina yang sama digunakan secara monokular dan binokular.

2. Mikrotropia sekunder yang terjadi setelah koreksi bedah atau koreksi optik dari strabismus sudut besar atau yang berhubungan dengan kelainan mata lainnya. Pada bentuk ini bisa disertai ambliopia pada satu mata atau tidak ada sama sekali.

\section{Gambaran Klinis Mikrotropia}

Beberapa petunjuk atau gejala dari mikrotropia :1,3,11

1. Sudut deviasi yang kecil yaitu 8-10 PD

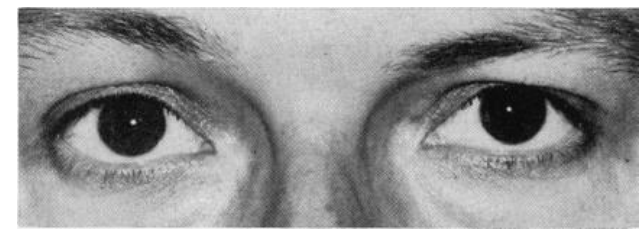

Gambar 3. Mikrotropia primer pada mata kanan ${ }^{11}$

2. Penurunan tajam penglihatan pada mata yang mengalami deviasi. Tajam penglihatan pada mata yang mengalami mikrotropia dapat mencapai 6/12-6/9.

\section{Ambliopia}

Ambliopia biasanya terjadi karena adanya defek pada penglihatan sentral, sedangkan penglihatan perifer biasanya normal. Pada sebagian besar pasien mikrotropia terutama mikrotropia primer mempunyai gejala ambliopia tetapi presentasenya bervariasi tergantung penyebabnya.

4. Fiksasi eksentrik

Pada mikrotropia, hilangnya fiksasi sentral disebabkan karena timbulnya skotoma supresi sentral. Jika besar derajat eksentriknya sama dengan besarnya sudut deviasi, mata tidak bergerak pada pemeriksaan cover test, tapi apabila besar eksentrik lebih kecil dari deviasi, maka pada pemeriksaan cover test akan terlihat sedikit gerakan.

5. Skotoma supresi sentral

Pada pasien dengan mikrotropia terdapat skotoma dengan supresi sentral yang kecil dan fusi perifer. Hal ini terjadi karena bagian sentral retina mempunyai lapangan persepsi yang lebih kecil dengan sensitivitas yang tinggi terhadap perbedaan ukuran bayangan antara kedua mata. Sedangkan pada retina perifer lapangan persepsi lebih luas dengan sensitivitas yang rendah terhadap ukuran bayangan sehingga masih bisa dihasilkan fusi perifer. Sehingga posisi mata yang lurus bisa dipertahankan dengan adanya fusi perifer ini.

6. ARC berasal dari perkembangan strabismus dengan deviasi lebih dari

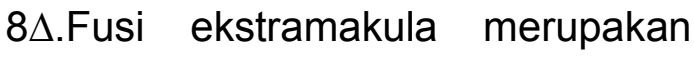
adaptasi ARC untuk mengeliminasi diplopia dan visual confusion pada bagian perifer lapangan pandang binokular. Pada microtropia with identity tidak terdapat gerakan mata yang deviasi waktu pemeriksaan dengan cover test (harmonious 
anomalous retinal correspondence). Sedangkan pada microtropia without identity, terdapat sedikit gerakan mata pada cover test (unharmonious anomalous retinal correspondence).

7. Stereopsis derajat rendah.

Penglihatan tiga dimensi pengertiannya sama dengan penglihatan binokular atau stereopsis. Dengan kata lain, stereopsis itu merupakan kemampuan untuk menerima persepsi kedalaman berdasarkan disparitas bayangan yang dibentuk oleh kedua mata. Proses stereopsis ini terganggu karena beberapa faktor seperti gangguan refraksi, perbedaan sensitifitas kontras antara kedua mata dan strabismus. Pada mikrotropia akan dijumpai penurunan kemampuan stereopsis.

\section{Pemeriksaan Mikrotropia}

Diagnosis akurat ditegakkan bila pada pemeriksaan klinis ditemukan hilangnya penglihatan binokuler sentral (bifiksasi) dan terdapatnya fusi perifer. Meskipun kelainan motorik sering dijumpai pada mikrotropia, namun diagnosis baru bisa ditegakkan setelah dilakukan pemeriksaan sensorik. Pemeriksaan yang bisa dilakukan adalah: ${ }^{12}$

1.Pemeriksaan visus dengan Snellen Chart.

2. Cover Test

Pada pasien dengan ortoforia, masing-masing mata menyesuaikan diri dengan objek fiksasi. Oleh sebab itu menutup salah satu mata tidak menimbulkan gerakan fiksasi pada mata sebelahnya. Pada pasien mikrotropia, hasil pemeriksaan dengan cover test tergantung dari pola fiksasinya. Apabila belum terjadi fiksasi eksentrik, akan terjadi gerakan yang halus/ sedikit pada pemeriksaan cover test $t^{1,4,12}$. Cover test bisa mengungkap ada atau tidak adanya deviasi laten, yaitu pada pasien dengan microtropia with identity atau pada microtropia without identity dengan deviasi manifest kecil $\left(<5^{\circ}\right)$. Deviasi manifest kecil biasanya terlihat, kecuali pada microtropia with identity ${ }^{1,6}$.

3. Fiksasi

Saat mata normal berfiksasi, bayangan akan jatuh di foveola yang terletak di pusat dalam fovea. Titik fiksasi bisa diklasifikasikan menjadi fiksasi sentral (foveolar) dan eksentrik. Pada fiksasi eksentrik, area retina yang digunakan untuk fiksasi adalah di parafoveolar atau di parafovea atau bisa juga di perifer (di luar fovea) (gambar 4). Fiksasi parafovea sering terlihat pada banyak kasus mikrotropia. Pemeriksaan fiksasi dengan oftalmoskop yang dikenal dengan visuskop yang berguna untuk mendiagnosa bentuk fiksasi ${ }^{5,6}$.

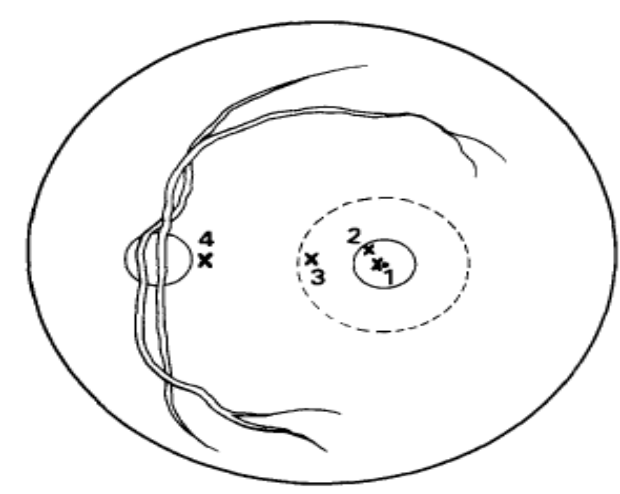

Gambar 4. Titik fiksasi. (1) parafoveolar, (2) parafovea, (3dan4) perifer. ${ }^{6}$

4. $4 \Delta$ base out prism test

Skotoma sangat mudah di deteksi dengan $4 \Delta$ base out prism test. 
Pemeriksaan ini merupakan pemeriksaan objektif yang berguna untuk memperlihatkan adanya skotoma pada mikrotropia atau bisa digunakan untuk membedakan antara bifoveal fiksasi dengan skotoma supresi sentral.Bila prisma diletakkan pada mata yang mikrotropia (OS), maka tak ada gerakan pada mata kanan. Bila diletakkan pada mata yang normal (OD) maka akan terlihat gerakan kedua mata ke kiri (gambar $5)^{3,7}$.

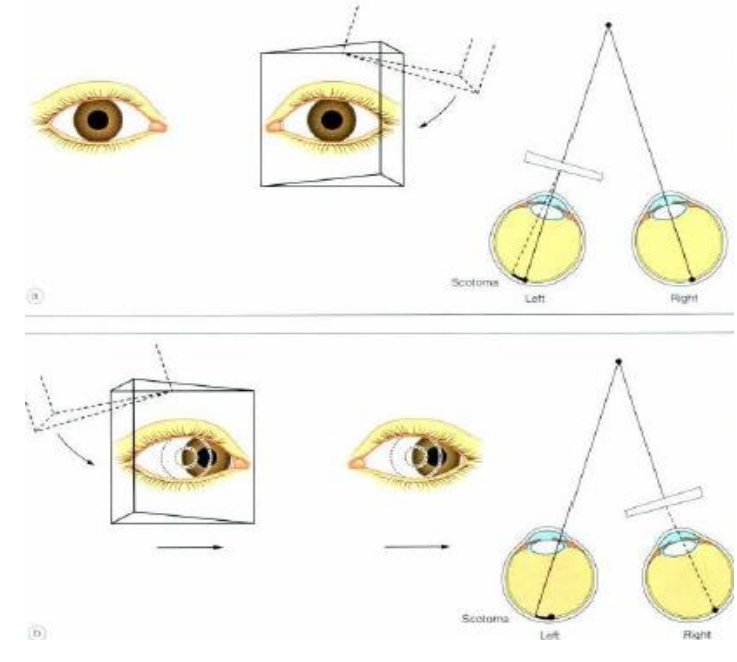

Gambar 5. $4 \Delta$ prism test pada mikrotropia mata kiri dengan skotoma supresi sentral. (A) Tidak ada pergerakan pada kedua mata, (B) Kedua mata bergerak ke kiri tapi tidak ada refiksasi ${ }^{10}$.

\section{Bagolini striated glasses}

Pemeriksaan ini merupakan tes yang cepat, sederhana dan informatif untuk ARC pada pasien strabismus. Lensa Bagolini terdiri dari lensalensa optik plano dengan alur-alur halus yang sama sekali hampir tidak membuat kabur penglihatan seke- lilingnya, tetapi bila kaca ini untuk melihat titik sumber cahaya maka akan tampak sebagai garis terang ${ }^{1,4}$. Lensa dengan strip-strip ini ditempatkan demikian rupa sehingga strip itu pada posisi 45 derajat pada mata kiri dan 135 derajat pada mata kanan, sehingga saat cahaya melewati lensa menghasilkan garis yang membentuk sudut 90 derajat pada satu dengan yang lainnya (gambar $6)^{1,4}$. Pasien kemudian diarahkan ke sumber cahaya pada jarak 1/3 dan 6 meter dan diminta untuk menggambarkan pada selembar kertas apa yang dilihat oleh pasien (jumlah garis serta posisi garis yang terlihat). Apabila pasien melihat dua garis, maka ditanya apakah garis tersebut bersilangan atau terpisah, terlihat menetap atau kadang-kadang menghilang. Jika kedua garis tadi terlihat bersilangan, tanyakan juga apakah terdapat celah atau gap pada salah satu garis. Hal ini disebabkan karena adanya ARC dengan adanya titik fiksasi di skotoma pasien yang menderita mikrotropia (tabel 1) 2,3,13.

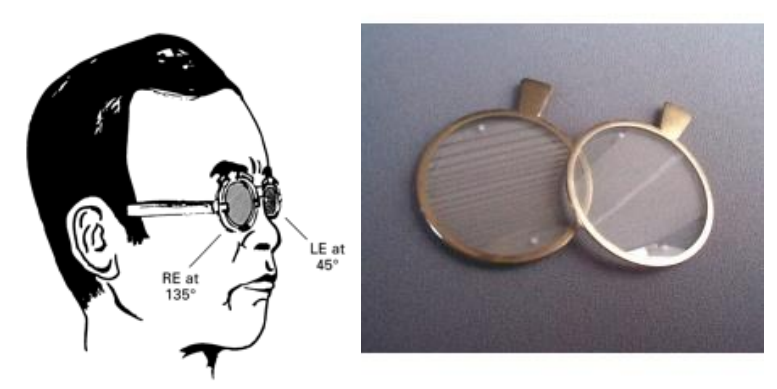

Gambar 6. Lensa Bagolini yang di letakkan pada trial frame dengan the axis dari striation pada sudut $135^{\circ}$ pada mata kanan dan $45^{\circ}$ pada mata kiri ${ }^{3}$ 


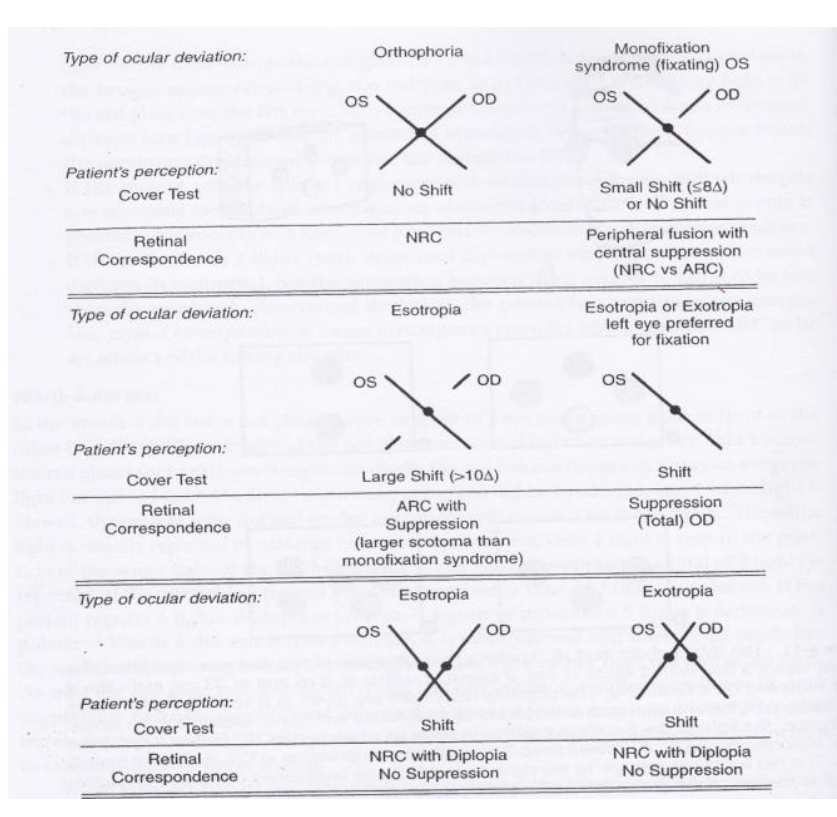

Tabel 1. Interpretasi pemeriksaan Bagolini striated glass ${ }^{4}$

\section{Worth Four Dot Test (WFDT)}

WFDT merupakan untuk menilai fusi dan supresi pada jarak dekat dan jauh. Pemeriksaan ini terdiri dari susunan empat buah titik yang disusun sedemikian rupa, yang biasanya berupa titik merah, putih dan dua titik hijau (gambar 7). Pasien memakai kacamata red filter terletak didepan satu mata dan green filter pada mata yang lain. Cahaya merah dapat dilihat oleh mata yang tertetak dibelakang lensa merah, tetapi cahaya hijau tidak tampak karena lensa merah menyerap panjang gelombang cahaya hijau. Sebaliknya pada lensa hijau dapat melihat cahaya hijau, tetapi tidak cahaya merah ${ }^{14}$.

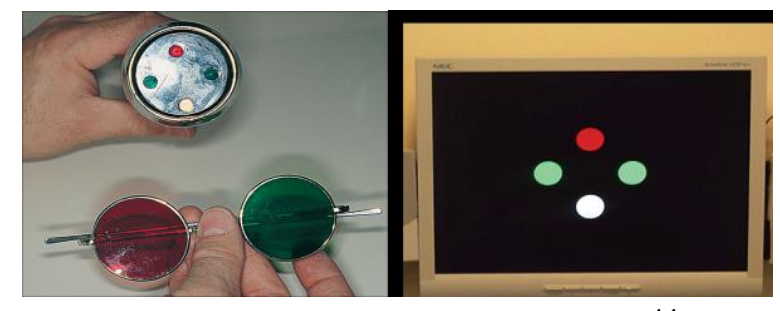

Gambar 7. Near and distance WFDT ${ }^{14}$
Pasien melihat pada sebuah target yang terdiri dari empat titik cahaya, yaitu satu merah, dua hijau, dan satu putih. Saat melihat target tersebut pada jarak jauh (6 meter), akan menstimulasi primary central vision. Ketika pasien melihat keempat titik cahaya tersebut pada jarak $33 \mathrm{~cm}$, peripheral fusion yang akan terstimulasi ${ }^{14,15,16}$.

\section{Prosedur pemeriksaan WFDT: 3,14,17}

a. Pasien harus menggunakan kedua matanya untuk melihat 4-dot pada waktu yang bersamaan.

b. Jangan izinkan pasien melihat 4-dot sebelum pasien menggunakan kacamata red-green.

c. Perintahkan pasien menggunakan kacamata red-green. Mata yang memakai filter merah akan melihat cahaya merah, sebaliknya mata yang menggunakan filter hijau akan melihat cahaya hijau.

d. Pastikan pasien berada di jarak 6 meter untuk pemeriksaan jarak jauh dan $33 \mathrm{~cm}$ atau posisi baca untuk pemeriksaan dekat. Dan pastikan ruangan pemeriksaan dalam keadaan terang. Membandingkan bayangan hasil WFDT pada jarak 6 meter dengan 0,33 meter merupakan salah satu cara yang terbaik untuk menegakkan mikrotropia atau sindroma monofiksasi. Pada jarak 0,33 meter (near WFDT) ke-4 titik akan terlihat secara jelas karena ke empat titik ini difusikan pada 6 derajat sehingga semua titik terdapat di luar skotoma. Sedangkan pada jarak 6 meter (distant WFDT), pasien akan melihat 2 titik karena titik difusikan pada 1.25 derajat sehingga terdapat di area skotoma (gambar 8) 4,13,18,19. 


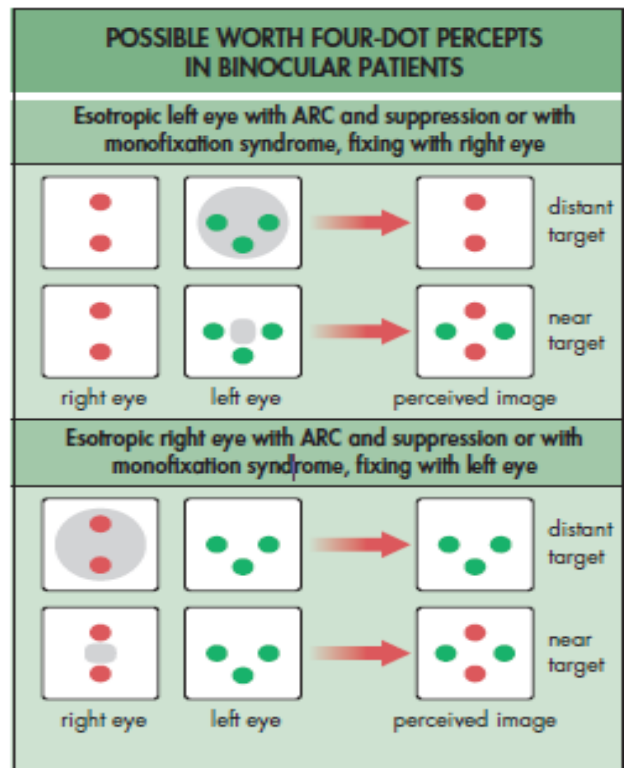

Gambar 8. Hasil pemeriksaan pada pasien dengan esotropia dengan ARC dan supresi dan dengan monofixation syndrome (mikrotropia) ${ }^{14}$

7. Stereoacuity test adalah pengungkapan kuantitatif stereopsis yang dirancang untuk mengukur kemampuan seseorang dalam mendeteksi jumlah disparitas image retina dalam konteks pandangan binokular. Stereoacuity ini dinyatakan dalam detik busur. Tajam penglihatan stereoskopis seseorang bisa ditentukan dengan pemeriksaan TNO test serta Titmus stereofly plate test (yang ketajamannya 3000 detik busur) (gambar 9 dan 10) ${ }^{1,4,20}$.

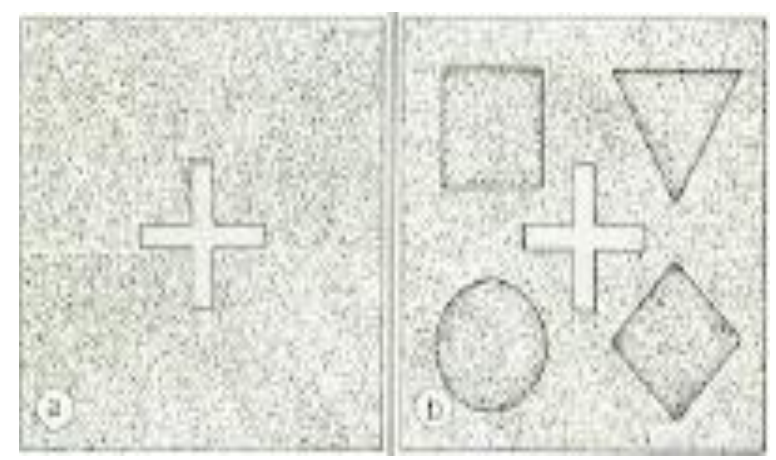

Gambar 9. TNO test ${ }^{10,18}$

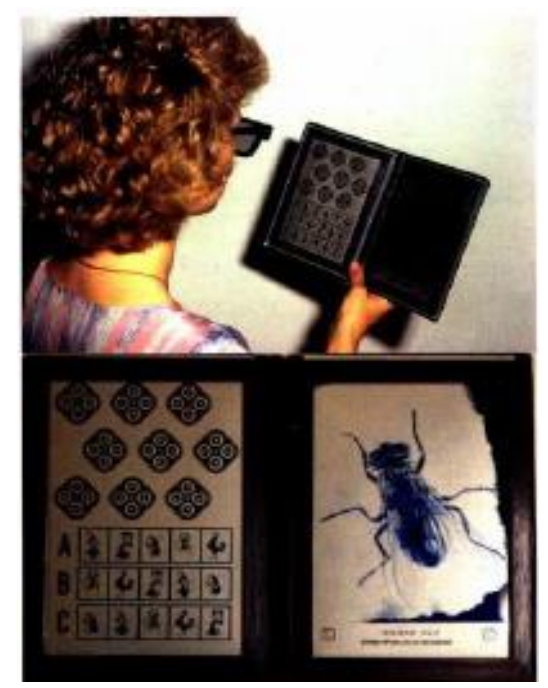

Gambar 10. Titmus test ${ }^{10}$

Pada pemeriksaan TNO, digunakan sebuah buku yang tiap lembarnya ada gambar yang dibentuk oleh titik-titik merah dan hijau yang tersusun sedemikian rupa yang memberikan kesan tiga dimensi, bila dilihat dengan kacamata merah hijau. Pada lembaran pertama terdapat gambar kupu-kupu yang merupakan objek dengan stereoskopik kasar (2000 detik busur) yang bisa dilihat dengan satu mata (tanpa kesan ruang atau tiga dimensi), dan lembar selanjutnya terdapat gambar yang hanya dapat dilihat dengan tiga dimensi yang mempunyai ketajaman stereoskopik ${ }^{4,14,15,19}$.

Tiap lembar mempunyai tajam penglihatan stereoskopik dengan disparitas yang berbeda-beda mulai dari yang halus (15 derajat busur) sampai yang kasar (480 derajat busur). Pemeriksaan dilakukan dengan memakai kaca mata merah dan hijau (hijau pada mata kanan) pada jarak $40 \mathrm{~cm}$ dari mata pasien. Normalnya akan dapat melihat gambar dengan ketajaman stereoskopik 68 detik busur atau lebih baik, sedangkan pada tajam penglihatan stereoskopik lebih jelek dari 40 detik busur bisa saja disebabkan oleh kelainan refraksi, strabis- 
mus, deprivasi atau terdapat kelainan organik ${ }^{4,16,17,20 .}$.

Pada mikrotropia terdapat stereosis derajat rendah, dimana pada sebagian besar pasien didapatkan ukuran 200-3000 detik busur ${ }^{4,6}$.

\section{Afterimage test}

Suatu kesatuan dari arah respon sensori pada setiap mata dapat diartikan sebagai afterimage. Afterimage memiliki kekhasan objek nyata dan berlangsung lama setelah stimulus asli berhenti ${ }^{4,7}$. Pemeriksaan ini sangat penting untuk mendiagnosis suatu ARC yang menggunakan camera flash untuk memproduksi afterimage vertikal pada satu mata dan afterimage horizontal pada mata lainnya. Bagian sentral dari flash ditutup dengan penanda hitam (digunakan sebagai titik fiksasi dan proteksi fovea). Pemeriksaan ini melibatkan stimulus dari makula pada masing-masing mata dengan garis afterimage yang berbeda, satu horizontal dan satu vertikal. Afterimage vertikal diletakkan pada mata yang deviasi dan horizontal pada mata yang berfiksasi. Pasien menunjukkan posisi relatif dua bagian yang terputus (two gaps) di tengah masing-masing afterimage $^{4,7}$.

Interpretasi dengan fiksasi sentral adalah (gambar 12): ${ }^{4}$

- Persilangan yang simetris dengan adanya gap sentral yang berimpit mengindikasikan NRC.

- Pasien dengan esotropia kiri melihat afterimage vertikal terletak di kanan dan pada kasus eksotropia kiri pasien melihat afterimage vertikal berada di kiri.

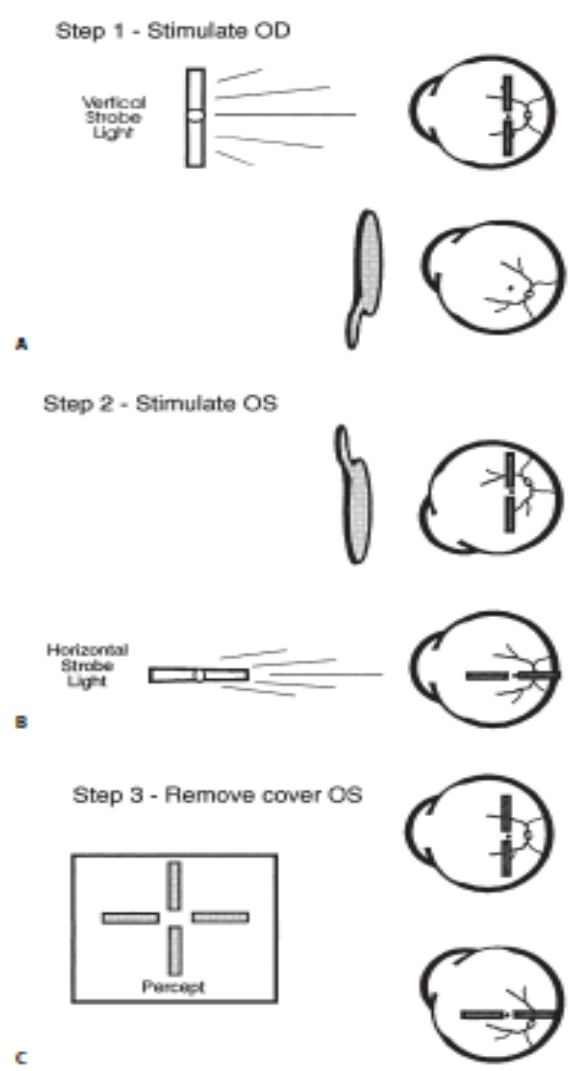

Gambar 11. Cara pemeriksaan after image $^{7}$
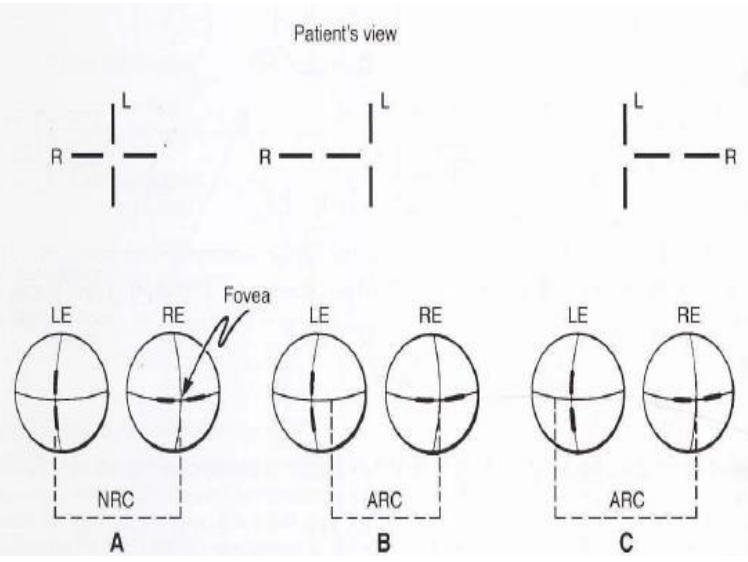

Gambar 12. After image test. A. Normal (cross) pada NRC. B. Anomalous crossed localization pada esotropia. C. Anomalous uncrossed localization pada eksotropia 4 . 


\section{Bruckner test}

Pemeriksaan ini biasanya digunakan sebagai screening. Pemeriksaan dilakukan dengan melihat reflek fundus memakai oftalmoskop pada jarak $75 \mathrm{~cm}$ untuk mencari kelainan refraksi, strabismus dengan 4 atau lebih prisma dioptri, anisometropia dengan 1 atau lebih prisma dioptri. Reflek fundus pada mata yang deviasi terlihat lebih terang dari mata yang fiksasi ${ }^{21}$.

\section{SIMPULAN}

Mikrotropia merupakan strabismus sudut kecil (8-10 prisma dioptri), dimana terjadi fusi di daerah perifer dan supresi di area sentral pada mata yang berdeviasi. Ada dua bentuk dari mikrotropia yaitu mikrotropia primer dan sekunder. Gambaran klinis dari mikrotropia adalah sudut deviasi yang kecil dari 8 prisma dioptri, ambliopia, fiksasi eksentrik, fusi perifer, Abnormal Retinal Correspondence (ARC) dan stereopsis derajat rendah.Cover test, WFDT, $4 \Delta$ base out prism test, bagollini striated glasses test, after image test, bruckner test dan stereoacuity merupakan beberapa pemeriksaan untuk menegakkan diagnosa mikrotropia.

\section{DAFTAR RUJUKAN}

1. Housten A Charlotte, Clearly M. Dutton G, McFazean R. Clinical characteristic of microtropia - is microtropia a fixed phenomenon?. Br.J. Ophthalmol. 1998: 82(3);219-24.

2. Tomac S, Sener C. Sanac AS. Clinical and Sensorial Characteristics of
Microtropia. Jpn J Ophthalmol. 2002:46(1);52-8.

3. Kanski J Jack, Bowling B. Clinical Opthalmology: A Systemic Approach [online]. Strabismus. Seventh Edition; 2011.

4. Skuta GL, Cantor LB, Weiss JS. Sensory Physiology and Pathology. In: Pediatric Ophthalmology and Strabis-mus. American Academy of Ophthal-mology. San Francisco; 2011.

5. Schlote T, Rohrbach J. Strabismus. In: Pocket Atlas of Ophthalmology. New York; 2006:p.50-65.

6. Anson M Alec, Davis Helen. Diagnosis and Management of Ocular Motility Disorders. Microtropia and Allied Conditions. Third Edition. 2001:p.305-311.

7. Tsai C James. Binocular Single Vision. In: Strabismus. Oxford American Handbook of Ophthalmology; 2011:p.575-580.

8. Hoyt S Creig, Taylor David. Pediatric Ophthalmology and Strabismus [online]. Special esotropias (acute comitant, sensory deprivation, myopia associated and microtropia). Fourth Edition; 2013:p779-782.

9. Tindall R, Jensvold B. Current Ocular Therapy. Monofixation Syndrome. Sixth Edition; 2008:p.421-423.

10. Kanski J Jack,Bowling B. Synopsis of Clinical Ophthalmology [online]. Strabismus. Seventh Edition; 2011: p.321-333.

11. Rustein P Rober, Cogen S. Optometric Clinical Practise Guideline. Strabismus: esotropia and exotropia. American Optometric Association; 2010:pp.23-35.

12. Billson F. Strabismus. Fundamentals of Clinical Ophthalmology ;2003 : p60-66.

13. Parks MM. Monofixation Syndrome. In: Duanne Clinical Ophthalmology, Tasman W editor. Vol 3;1997.

14. Yanoff, Myron and Duke S Joy. Sensory Status in Strabismus. In, Ophthalmology. Fourth Edition. 2014:p.-1201-05.

15. Matsuo T, Kawaishi $\mathrm{Y}$, Kuroda R, Ohtsuki H, Watanabe Y. Long-term Visual Outcome in Primary Microtropia. Japanese Ophthal-mological Society. 2003: 47(5);507-11.

16. David B, Elliott. Assessment of Binocular Vision and Accomodation. In, Primary Eye Care. Fourth Edition. 2014: p. 147208.

17. Ophtalmic Assistant. In: Ocular Motility and Binocular Vision. Ninth Edition. Chapter 39:2013. p.656-66.

18. Albert and Jakobiec. Clinical Evaluation of Strabismus. In: Principles and Practise of Ophthalmology. Third Edition. Chapter 314: 2008. P.4305-13. 
19. Levin A, Leonard, Nillson FE Siv. Binocular Vision. In: Adler's Physiology of the Eye. Eleventh Edition; 2011:p.677-697.

20. Siatkowski M. The Decompasated Monofixation Syndrome. An American Ophthalmological Society Thesis; 2011.
21.Lee W Lexa. Bruckner Test Useful for Detecting Reduced Vision in Children. American Academy of Ophthalmology. Annual Meeting; 2007. 